\title{
AVALIAÇÃO SENSORIAL E COMPOSIÇÃO PROXIMAL DE CAMARÕES DE ÁGUA DOCE Macrobrachium rosenbergii DEFUMADOS
}

\author{
Adriana Ferreira Silva, ${ }^{1}$ Leandro Cesar Godoy, ${ }^{1}$ Maria Luiza Souza Franco, ${ }^{1}$ \\ Michele Ferreira Assis, ${ }^{1}$ Nilson Evelazio Souza ${ }^{2}$ e Jesuí Vergilio Visentainer ${ }^{2}$ \\ 1. Universidade Estadual de Maringá, Departamento de Zootecnia. Av. Colombo, 1790, CEP 87020-900, Maringá, PR \\ E-mail: dri zootecnia@yahoo.com.br, godoyzoo@yahoo.com.br,mlrsouza@uem.com.br, tcheliassis@yahoo.com.br \\ 2. Universidade Estadual de Maringá, Departamento de Química. Av. Colombo, 1790, CEP 87020-900, Maringá, PR. \\ E-mail: jvvisentainer@uem.br, nesouza@uem.br
}

RESUMO

Este estudo avaliou o efeito da defumação e da presença de ervas aromáticas na qualidade do músculo do camarão Macrobrachium rosenbergii, por meio da análise das características sensoriais e da composição proximal. Foram utilizados 55 camarões com peso médio 33,9 $\pm 13,49 \mathrm{~g}$ insensibilizados com choque térmico. Após a remoção do cefalotórax e da carapaça, os camarões foram lavados, pesados, identificados, imersos em solução de salmoura (20\%) e em seguida defumados a uma temperatura de 50 a $90^{\circ} \mathrm{C}$. $\mathrm{O}$ delineamento experimental foi inteiramente casualizado, com dois tratamentos (T1 = camarão defumado com ervas aromáticas; $\mathrm{T} 2$ = camarão defumado sem ervas aromáticas) com 25 unidades experimentais por tratamento. Após a defumação, congelaram-se amostras $\left(-18^{\circ} \mathrm{C}\right)$ para análise de composição proximal e avaliaramse, sensorialmente, porções por um painel de quarenta provadores, mediante a utilização de um método de estímulo simples. Os camarões defumados apresentaram valores médios de proteína bruta $(44,72 \%)$, lipídios totais $(1,39 \%)$ e cinzas $(3,04 \%)$ superiores comparados aos dos camarões in natura $(16,80 \% ; 0,30 \%$ e $0,89 \%$ respectivamente). Não houve efeito significativo das ervas aromáticas na composição proximal dos camarões defumados e sua utilização não interferiu nas características sensoriais analisadas. Os camarões defumados tiveram boa aceitação pelos provadores.

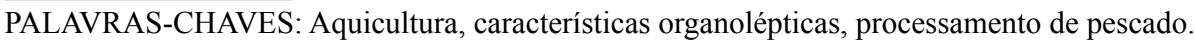

\section{ABSTRACT}

\section{SENSORY EVALUATION AND PROXIMATE COMPOSITION OF SMOKED FRESHWATER PRAWNS (Macrobrachium rosenbergii)}

This study evaluated the effect of smoking and the presence of aromatic herbs on the quality of freshwater prawns muscle (Macrobrachium rosenbergii), through the analysis of sensory characteristics and proximate composition. Fifty-five freshwater thermally stunned prawns, with average weight of $33.9 \pm 13.49 \mathrm{~g}$, were used. After cephalothoraxes and carapaces removal, the freshwater prawns were washed, weighed, identified, immersed in brine solution $(20 \%)$ and then smoked at a temperature of 50 to $90^{\circ} \mathrm{C}$. The experimental design was completely randomized with two treatments $(\mathrm{T} 1=$ smoked freshwater prawns with herbs; $\mathrm{T} 2=$ smoked freshwater prawns without herbs), with 25 experimental units per treatment. After smoking, samples were frozen (-18 C) for proximate composition analysis and portions were sensorially evaluated by 40 tasters based on a simple stimulus method. The smoked freshwater prawns showed medium values of crude protein (44.72\%), total lipids (1.39\%) and ashes (3.04\%) comparatively higher than the values of the in natura freshwater prawns $(16.80 \%$, $0.30 \%$ and $0.89 \%$, respectively). The aromatic herbs did not affect significantly the proximate composition of smoked freshwater prawns and their use did not interfere on the sensory characteristics evaluated. The smoked freshwater prawns had a good acceptance by the taster.

KEYWORDS: Aquaculture, fish processing, organoleptic characteristics. 


\section{INTRODUÇÃO}

A carcinicultura de água doce tem sido reconhecida como uma forma de produzir crustáceos com baixo impacto ambiental, pois se adapta muito bem aos sistemas familiares de produção e atende aos preceitos da aquicultura sustentável (NEW \& VALENTI, 2001). Atualmente essa atividade vem mostrando maturidade na conquista de novos e importantes mercados, levando o camarão à mesa dos brasileiros e desmistificando costumes (VALENTI \& MORAES-RIODALES, 2004).

O camarão de água doce (Macrobrachium rosenbergii), conhecido popularmente como gigante da Malásia, é uma das mais importantes espécies de crustáceo produzida na aquicultura continental em muitos países tropicais e subtropicais ao redor do mundo (THANH et al., 2009). Seu cultivo comercial tem se expandido na Ásia, com aumento da produção mundial de 18.451 toneladas em 1990 para 203.903 toneladas em 2005 (FAO, 2005), com um valor estimado de mercado que excedeu US\$ 810 milhões.

Os pescados, em geral, são produtos altamente perecíveis, dada a elevada atividade de água, a composição química, o teor de gorduras insaturadas facilmente oxidáveis e, principalmente, o $\mathrm{pH}$ próximo da neutralidade (MELO FRANCO \& LANDGRAF, 1996). Graças a essas características intrínsecas, os processos de conservação do pescado in natura e de transformações tecnológicas ganham importância especial (SOUZA et al., 2004; GODOY et al., 2010).

A defumação, embora seja uma antiga técnica de conservação, tem sido utilizada, atualmente, como um artifício para melhorar a qualidade dos pescados, uma vez que provoca mudanças nos atributos sensoriais como odor, sabor, coloração e textura (SIGURGISLADOTTIR et al., 2000). Além disso, tem como finalidade estender a vida útil do produto, em virtude dos efeitos combinados da salga, cocção, secagem e deposição de substâncias químicas bactericidas presentes na fumaça, como fenóis, aldeídos e ácidos orgânicos (ASSIS et al., 2009). O êxito na preparação de defumados depende da aplicação da fumaça e da combinação de fatores físicos e químicos, sendo necessário um controle rigoroso de cada uma das etapas (GONÇALVES \& PRENTICEHERNANDEZ, 1998).

Com este trabalho objetivou-se avaliar o efeito da defumação e aplicação de ervas aromáticas na com- posição proximal e características sensoriais de camarões de água doce Macrobrachium rosenbergii.

\section{MATERIAL E MÉTODOS}

\section{Amostras}

Utilizaram-se 55 exemplares de Macrobrachium rosenbergii com peso médio $33,9 \pm 13,49 \mathrm{~g}$, provenientes de um cultivo da região de Maringá, PR. O delineamento experimental foi inteiramente casualizado com dois tratamentos $\left(\mathrm{T}_{1}=\right.$ camarões defumados com ervas aromáticas; e $\mathrm{T}_{2}=$ camarões defumados sem ervas aromáticas), com 25 unidades experimentais por tratamento, sendo o camarão considerado a unidade experimental. Os camarões foram lavados e insensibilizados com choque térmico, por imersão em uma mistura de água e gelo moído (1:1), durante dez minutos.

Após a pesagem (balança digital), retiraramse o cefalotórax e a carapaça, sendo lavados em água clorada (5 ppm) e novamente pesados. Em seguida, foram embalados individualmente em sacos de tule e identificados com placa metálica numerada, distribuídos aleatoriamente em dois lotes, para a defumação com e sem ervas aromáticas. Imergiram-se os camarões em solução de salmoura a $20 \%$, na proporção de $2: 1$ (volume da salmoura/peso), por quinze minutos. Para o tratamento com ervas aromáticas, uma mistura de orégano, cebola, alho, alecrim, manjericão, louro, cebolinha e salsinha desidratadas foi triturada em multiprocessador e incluída na solução de salmoura (52 g da mistura/L de salmoura).

\section{Processo de defumação}

Após a salga, lavaram-se os camarões em água corrente para eliminar o excesso de sal da superfície, a fim de se evitar a formação de cristais durante a defumação, sendo drenados por uma hora, para perda da água superficial. Em seguida, foram distribuídos aleatoriamente dentro da câmara de defumação (defumador artesanal com geração de fumaça externa à câmara de defumação) para secagem parcial a $50^{\circ} \mathrm{C}$ por sessenta minutos. Decorrido esse período, iniciou-se a adição da fumaça, utilizando como fonte a serragem de eucalipto rosa (Eucalyptus globulus Labill) e, 
para manutenção da temperatura, o gás de cozinha (ASSIS et al., 2009).

A temperatura da defumação iniciou-se com $50{ }^{\circ} \mathrm{C}$ e atingiu $90^{\circ} \mathrm{C}$ na última hora de defumação, com acréscimo de $20^{\circ} \mathrm{C}$ a cada hora, totalizando duas horas de exposição dos camarões à fumaça. $\mathrm{O}$ produto defumado, após a pesagem, foi embalado em sacos plásticos. Estocaram-se as amostras destinadas à análise sensorial sob refrigeração $\left(5^{\circ} \mathrm{C}\right)$, e congelaram-se as demais $\left(-18^{\circ} \mathrm{C}\right)$ até o momento das análises.

Análises físico-químicas

Cinco camarões in natura e cinco provenientes de cada tratamento após a defumação foram triturados em multiprocessador até obter-se uma polpa homogênea. Utilizaram-se alíquotas desta polpa para as determinações da composição proximal.

Os teores de umidade, cinzas e proteína bruta foram determinados conforme AOAC (1995). Na extração dos lipídios totais, empregou-se o método BLIGH \& DYER (1959). Todas as análises foram realizadas em triplicata.

\section{Análise sensorial}

Para verificação da aceitabilidade do produto, porções dos camarões defumados (cerca de $5 \mathrm{~g}$ ) foram avaliadas sensorialmente 24 horas após a defumação por um painel de 40 provadores não treinados, visando atingir o consumidor comum. Os provadores receberam de maneira aleatória as amostras em pratos codificados e a ficha para análise sensorial. Avaliaram-se os atributos aroma, sabor, textura, cor, teor de sal e aceitação geral. Para tanto, foi utilizada uma ficha com escala hedônica de 9 pontos com extremos 1 (desgostei muitíssimo) e 9 (gostei muitíssimo), de acordo com DUTCOSKY (2007).
Análises estatísticas

Para a análise sensorial, empregou-se um delineamento em blocos casualizados (DBC), em que cada provador foi considerado um bloco, com quarenta repetições por tratamento. Os resultados de análise de composição proximal, assim como da análise sensorial, foram submetidos à análise de variância (ANOVA - one way) e as médias comparadas pelo teste de Tukey ao nível de 5\% de probabilidade.

\section{RESULTADOS E DISCUSSÃO}

\section{Composição proximal}

Com o processo de defumação os camarões sofreram alterações nos teores de umidade, proteína bruta, lipídios totais e cinzas (Tabela 1). Houve redução significativa $(p<0,05)$ da umidade e consequentemente concentração dos nutrientes, bem como um acréscimo no teor de cinzas decorrente da absorção de cloreto de sódio pelo músculo durante o processo da salmouragem.

Os camarões in natura apresentaram teor de umidade de 78,22\%, estando de acordo com OGAWA (1999), que relata valores de $60 \%$ a $85 \%$ de umidade para o músculo do pescado in natura. Os teores de proteína bruta, lipídios totais e cinzas do camarão in natura foram ligeiramente inferiores aos encontrados por KIRSCHNIK et al. (2006) para esta mesma espécie de camarão $(18,59 \% ; 0,29 \%$ e $1,35 \%$, respectivamente). Não houve diferença significativa $(\mathrm{P}>0,05)$ para os valores de umidade, proteína bruta, lipídios totais e cinzas entre camarões defumados com e sem ervas (Tabela 1).

TABELA 1. Composição proximal de camarões de água doce (Macrobrachium rosenbergii) in natura e defumados com e sem ervas aromáticas

\begin{tabular}{lcccc}
\hline Fonte de variação & $\begin{array}{c}\text { Umidade } \\
(\%)\end{array}$ & $\begin{array}{c}\text { Proteína bruta } \\
(\%)\end{array}$ & $\begin{array}{c}\text { Lipídios } \\
(\%)\end{array}$ & $\begin{array}{c}\text { Cinzas } \\
(\%)\end{array}$ \\
\hline In natura & $78,22 \pm 3,12 \mathrm{a}$ & $16,80 \pm 1,21 \mathrm{a}$ & $0,30 \pm 0,84 \mathrm{a}$ & $0,89 \pm 0,02 \mathrm{a}$ \\
$\mathrm{T}_{1}$ com ervas & $49,05 \pm 0,87 \mathrm{~b}$ & $43,56 \pm 1,04 \mathrm{~b}$ & $1,45 \pm 0,10 \mathrm{~b}$ & $2,99 \pm 0,08 \mathrm{~b}$ \\
$\mathrm{~T}_{2}$ sem ervas & $49,88 \pm 0,90 \mathrm{~b}$ & $45,89 \pm 0,13 \mathrm{~b}$ & $1,33 \pm 0,19 \mathrm{~b}$ & $3,10 \pm 0,03 \mathrm{~b}$ \\
\hline
\end{tabular}

*Para cada fator, médias na mesma coluna seguidas da mesma letra não diferem entre si pelo teste de Tukey $(\mathrm{P}>0,05)$. 
Os resultados do produto defumado estão de acordo com GONÇALVES \& PRENTICE-HERNANDEZ (1998), confirmando que em pescados defumados o conteúdo de proteína é mais alto que no pescado fresco.

TRAFICANTE et al. (2010) observaram valores de $2,39 \%$ e $2,85 \%$ de lipídios totais em camarões marinhos defumados com e sem ervas aromáticas, respectivamente, valores estes superiores aos observados nos camarões de água doce deste experimento. $\mathrm{O}$ teor de lipídios totais é superior em camarões marinhos comparados com camarões de água doce, em virtude do tipo de alimento disponível no meio. No ambiente marinho há grande disponibilidade de alimento natural, como zooplâncton e principalmente fitoplâncton, com elevados valores de ácidos graxos poli-insaturados, refletindo diretamente no teor de lipídios totais no músculo dos organismos que o consomem (BRAGAGNOLO \& RODRIGUEZ-AMAYA, 1997).

\section{Análise sensorial}

Não houve diferença significativa entre os tratamentos para todos os atributos avaliados (Tabela 2). Os provadores não notaram diferenças $(\mathrm{P}>0,05)$ quanto ao acréscimo de ervas aromáticas nos camarões defumados.

TABELA 2. Médias das notas atribuídas às porções de camarões de água doce Macrobrachium rosenbergii defumados

\begin{tabular}{lcccc}
\hline Atributos & Com ervas & Sem ervas & Teste F & C.V(\%) \\
\hline Aroma & $7,70 \pm 1,83 \mathrm{a}$ & $7,40 \pm 2,06 \mathrm{a}$ & $0,08 \mathrm{~ns}$ & 8,11 \\
Sabor & $7,57 \pm 1,65 \mathrm{a}$ & $7,30 \pm 2,02 \mathrm{a}$ & $0,08 \mathrm{~ns}$ & 8,64 \\
Textura & $6,53 \pm 1,67 \mathrm{a}$ & $6,63 \pm 1,89 \mathrm{a}$ & $0,26 \mathrm{~ns}$ & 10,42 \\
Cor & $6,80 \pm 1,78 \mathrm{a}$ & $7,03 \pm 1,94 \mathrm{a}$ & $0,09 \mathrm{~ns}$ & 5,13 \\
Teor de sal & $6,53 \pm 2,06 \mathrm{a}$ & $7,17 \pm 2,00 \mathrm{a}$ & $0,54 \mathrm{~ns}$ & 12,20 \\
Aceitação geral & $7,63 \pm 1,45 \mathrm{a}$ & $7,27 \pm 1,65 \mathrm{a}$ & $0,50 \mathrm{~ns}$ & 9,19 \\
\hline
\end{tabular}

*Para cada atributo, médias na mesma linha seguidas da mesma letra não diferem entre si pelo teste de Tukey $(\mathrm{P}>0,05)$.

Mesmo o camarão de água doce sendo considerado um pescado magro pelo baixo teor de lipídios $(<15 \%)$, razão por que não é indicado para defumação, conforme GEROMEL \& FORSTER (1982), os camarões defumados tiveram boa aceitação pelos provadores quanto às características sensoriais avaliadas. Este resultado deve-se à qualidade do pescado em questão e às características conferidas pela defumação. SOUZA et al. (2004) citam que, em alguns países, a defumação já não se constitui apenas em um método de preservação, mas uma forma de conferir sabor, cor e aroma típicos ao produto. Deve-se salientar, ainda, que a vida-de-prateleira do pescado defumado é sempre maior que a do pescado fresco, mantido nas mesmas condições. Com o processo de defumação pôde-se obter um produto característico por suas qualidades sensoriais, inovador e com valor agregado.

\section{CONCLUSÕES}

O processo de defumação alterou a composição proximal do camarão, promovendo uma concentração dos nutrientes. Não houve influência significativa das ervas aromáticas na composição proximal dos camarões defumados e sua utilização não interferiu nas características sensoriais analisadas. Os camarões defumados tiveram boa aceitação pelos provadores.

\section{AGRADECIMENTOS}

Ao Sr. Noda, pela doação dos camarões utilizados neste experimento. 


\section{REFERÊNCIAS}

AOAC. Oficial Methods of Analysis of the Association of Official Analytical Chemists. Arlington. 16. ed. AOAC, 1995. p. 1-30. Disponível em: http://www.aoac.org/Official_Methods/ slv_guidelines.pdf

ASSIS, M. F.; FRANCO, M. L. R. S.; STEFANI, M. V.; FRANCO, N.; GODOY, L. C.; OLIVEIRA, A. C.; VISENTAINER, J. V.; SILVA, A. F.; HOCH, A. L. V. Efeito do alecrim na defumação da carne de rã (Rana catesbeiana): características sensoriais, composição e rendimento. Ciência e Tecnologia de Alimentos, v. 29, n. 3, p. 553-556, 2009.

BLIGH, E. G.; DYER, W. J. A rapit method of total lipid estraction and purification. Canadian Journal of Biochemistry Physiology, v. 37, p. 911-917, 1959.

BRAGAGNOLO, N.; RODRIGUEZ-AMAYA, D. B. Otimização da determinação de colesterol por CLAE e teores de colesterol, lipídeos totais e ácidos graxos em camarão rosa (Penaeus brasiliensis). Ciência e Tecnologia de Alimentos, v. 17, n. 3, p. 75-80, 1997.

DUTCOSKY, S.D. Análise sensorial de alimentos. Curitiba: Champagnat, 2007. 210 p.

FAO. Fisheries and Aquaculture Department, Statistical Collections. Online Query Panels. FAO-FIGIS. Global aquaculture production: Food and Agriculture Organization of the United Nations. Rome. 2005. Disponível em: <http://www.fao.org/figis/servlet/ SQServlet?file=/usr/local/tomcat/FI/5.5.23/figis/webapps/figis/ temp/hqp_25606.xml\&outtype $=$ html $>$ Acesso em: abr. 2010.

GEROMEL, E. J.; FORSTER, R. J. Princípios fundamentais em tecnologia de pescados. Ciência e Tecnologia de Alimentos, n. 11, p. $127,1982$.

GODOY, L. C.; FRANCO, M. L. R. S.; FRANCO, N. P.; SILVA,A. F.; ASSIS, M. F.; SOUZA, N. E.; MATSUSHITA, M.; VISENTAINER, J. V. Análise sensorial de caldos e canjas elaborados com farinha de carcaças de peixe defumadas: aplicação na merenda escolar. Ciência e Tecnologia de Alimentos, v. 30, supl. 1, p. 86-89, 2010.

GONÇALVES, A. A.; PRENTICE-HERNÁNDEZ, C. Defumação líquida de anchova (Pomatomus saltatrix): efeito do processamento nas propriedades químicas e microbiológicas. Ciência e Tecnologia dos Alimentos, v. 18, n. 4, p. 438-443, 1998.
KIRSCHNIK, P. G. ; VIEGAS, E. M. M.; VALENTE, W. C.; OLIVEIRA, C. A. F. Shelf-life of tail meat of the Giant River Prawn, Macrobrachium rosenbergii, Stored on Ice. Journal of Aquatic Food Product Technology, v. 15, n. 2, p. 57-71, 2006.

MELO FRANCO, B. D. G.; LANDGRAF, M. Microbiologia dos alimentos. São Paulo: Atheneu, 1996. 182 p. Disponível em: http://gorpaki.blogspot.com/2010/06/microbiologia-dos-alimentos. html

NEW, M. B.; VALENTI, W. C. Freshwater prawn culture: the farming of Macrobrachium rosenbergii. Aquaculture International, v. 9, n. 5, p. 461-462, 2001.

OGAWA, M. Características específicas do pescado. In: OGAWA, M.; MAIA, E. L. Manual de pesca: ciência e tecnologia do pescado. São Paulo: Varela, 1999. v. 1, p. 9-15.

SIGURGISLADOTTIR, S.; SIGURDARDOTTIR, M. S.; TORRISSEN, O.; VALLET, J. C.; HAFSTEINSSON, H. Effects of different salting and smoking processes on the microstructure, the texture and yield of Atlantic salmon (Salmo salar) fillets. Food Research International, n. 33, p. 847-855, 2000.

SOUZA, M. L. R.; BACCARIN, A. E.; MACEDO-VIEGAS, E. M.; KRONKA, S. N. Defumação da tilápia-do-nilo (Oreochromis niloticus) inteira eviscerada e filé: aspectos referentes às características organolépticas, composição centesimal e perdas ocorridas no processamento. Revista Brasileira de Zootecnia,v. 33, n. 1, p. 27-36, 2004.

THANH, N. M.; PONZONI, R. W.; NGUYEN, H. N.; VU, N. T.; BARNES, A.; MATHER, P. B. Evaluation of growth performance in a diallel cross of three strains of giant freshwater prawn (Macrobrachium rosenbergii) in Vietnam. Aquaculture, v. 287, p. 75-83, 2009.

TRAFICANTE, D. P.; FRANCO, M. L. R. S.; GODOY, L. C.; FRANCO. N. P.; SILVA, A. F.; ASSIS, M. F.; SOUZA, N. E.; VISENTAINER, J. V. Composição química, análise sensorial e rendimento de camarões marinhos (Litopenaeus vannamei) defumados com ervas aromáticas. Semina, 2010. [In press].

VALENTI, W. C.; MORAES-RIODALES, P. M. C. Moorphotypes in male Amazon River Prawns, Macrobrachium amazonicum. Aquaculture, v. 236, n. 1-4, p. 297-307, 2004. 